\title{
Indicators of global university rankings: the theoretical issues
}

\author{
Nemanja Lukić \\ University of Novi Sad, Faculty of Education in Sombor, Sombor, Serbia \\ Pere Tumbas \\ University of Novi Sad, Faculty of Economics in Subotica, Subotica, Serbia
}

\begin{abstract}
The main goal of this paper is to determine the significance of identified university ranking indicators in relation to the overall measurement system of selected global ranking systems. The realisation of the research was divided into two phases. The first phase consists of a systematic overview of the literature that has resulted in the identification of 16 global ranking systems. In the second phase, an empirical analysis of 10 active ranking systems which were selected based on the set criteria. The ranking systems are observed regarding their measurement focus. According to the results of empirical analysis, the research category indicators account for $67.93 \%$ of the sum of the weight coefficients in the overall measurement system, followed by the reputation category indicators with $13.5 \%$ and the web performance category indicators with $9.37 \%$. The most significant number of global ranking systems dominantly puts its focus in the context of measuring research performance as the crucial indicator of the quality and competitiveness of universities.
\end{abstract}

\section{Keywords}

University, Global ranking System, Indicators

\section{Introduction}

The evolution of the global economy, accompanied by the transformation of the labor market (Chessell, 2018; Grossman, 2018) and the increasing level of human-machine collaboration (Bolton, Machová, Kovacova, \& Valaskova, 2018), is fueling new educational and research trends that have significant impact on evaluation and the modification of the global higher education market. The knowledge economy becomes the basis for the development of the worldwide economy. Universities are beginning to emerge as complex organizational systems made up of a mix of complex technical and infrastructure solutions as a result of emerging global challenges. As a result of the massification of the higher education market, the emergence of an increasing number of universities has led to the development of global ranking systems. It is precisely the global ranking systems that set the criteria for defining the difference in the quality of research and higher education institutions. The primary purpose of such systems is to assist key stakeholders (students and parents, industry, media organizations, etc.) in selecting institutions whose characteristics will suit their preferences.

Global ranking systems do not represent a new phenomenon in measuring the position of a university, but only a "variation of the old idea of national ranking systems" (Usher \& Savino, 2007, p. 6). Unlike national ranking systems, global systems approach university analysis using a set of indicators that are primarily and mainly focused on measuring the performance of the research process.

It can be noted that in the research of quality, similarity and difference, as well as the interconnection of individual global systems of university ranking and the related criteria, different methods and techniques of data analysis are used, according to analyzed relevant literature. Descriptive statistics are used to measure the central tendency (Çakır, Acartürk, Alaşehir, \& 
Çilingir, 2015; Khosrowjerdi \& Kashani, 2013; Olcay \& Bulu, 2017). When determining the strength of the relationship between the individual ranking systems and the indicators they use, the Spearman's correlation (Chen \& Liao, 2012; Khosrowjerdi \& Kashani, 2013; Moed, 2017; Shehatta \& Mahmood, 2016) and Pearson's correlation were used (Claassen, 2015; DelgadoMárquez, Hurtado-Torres, \& Bondar, 2011; Olcay \& Bulu, 2017; Shehatta \& Mahmood, 2016; Waltman et al., 2012).

The determination of the similarities between the individual ranking systems was carried out using the method of overlapping of the ranks (Aguillo, Bar-Ilan, Levene, \& Jose Ortega, 2010; Olcay \& Bulu, 2017), then the analysis of the inverse rank (Aguillo et al., 2010) as well as Spearman's footrule (Aguillo et al., 2010). The assessment of the quality dimensions of the global systems was carried out by the development of the factor model (Claassen, 2015), as well as the identification of the factor structure of the indicator to determine the impact of the identified factors on the overall score of the ranking system (Soh, 2015). In some comparative studies, the difference between the measurement systems was examined indicating the significance of certain indicator categories within the overall measurement system (Çakır et al., 2015; Olcay \& Bulu, 2017; Vernon, Andrew Balas, \& Momani, 2018).

In order to evaluate the usefulness of the ranking system and to identify opportunities for improving research performance, Vernon et al. (Vernon et al., 2018), by conducting a systematic review of literature, recognised 13 systems of university ranking, which form the basis of their research. Analysing the validity and sustainability of ranking system with respect to the indicators they contain, Vernon et al. (2018) conclude that it is necessary to make some improvements to the existing ranking system's methodologies, further suggesting that an ideal ranking system must reduce the proportion of weight coefficients for reputation measurement to be less than $10 \%$. In the end, even though the authors stated that all selected systems represent ranking systems of universities, one of them does not seem to satisfy the characteristics of the ranking system. It is the "Carnegie Classification", a system that primarily has the role of a framework for the recognition and description of the university.

In a comparative study, Cakir et al. (2015) observe the indicators of global and national ranking systems from the aspect of the dimensions and categories to which they belong, the frequencies of specific categories within the measurement system, and the significance of the indicators according to the weight coefficients assigned to them. According to the results of the research, they conclude that national ranking systems are more focused on educational and institutional parameters, unlike global systems focusing primarily on measuring the research performance of the university.

Finally, of all the available research studies that are directed to comparative analysis of the ranking system (Çakır et al., 2015; Moed, 2017; Vernon et al., 2018), none gives an emphasis on determining the proportion of values of certain weight coefficients in the total system of evaluation of global ranking systems. Following the above, two research questions have identified in the paper:

RQ1: What indicators are used in the global ranking systems of universities?

RQ2: What is the difference in significance between different groups of indicators of the university ranking system?

Responding to the first raised research question requires the initial identification of the most important global ranking systems of universities in the relevant available literature and indicators used in them. Subsequently, based on the empirical data obtained from the selected studies, it is necessary to identify and analyse the ranking criteria and to perform the comparison, organisation and transformation of the weight coefficients of the identified criteria within the defined criteria groups in order to give a response to another research question. Finally, it is necessary to transform the weighted coefficients of the indicators to show their importance in the overall measurement system.

Accordingly, the main objective of the research is to determine the significance of the identified indicators related to the overall system of measurement of the selected global ranking systems of universities.

\section{Methodology of research}

In the realisation of the first phase of theoretical research, the method of literature analysis was used. It is a selected method of a systematic review of literature, which was carried out to identify the global ranking systems of the university in the relevant literature. The second phase of the research was conducted by the 
empirical analysis of the active ranking systems identified within the first phase of the research.

\subsection{A systematic review of the literature}

The literature search was carried out according to the established working framework and guidelines (Kitchenham, 2004). A systematic review of the literature was preceded by the development of a protocol that included the definition of the goal of literature search, identification of keywords in the search, identification of the inclusive and exclusionary search terms, as well as the identification of the electronic databases for the search of scientific materials. In the end, all works identified in the search process are subject to evaluation through the criteria for evaluating scientific material.

The goal of the systematic literature search is to identify global ranking systems that have been the subject of comparative studies.

The search for scientific material lasted for three months and was completed in January 2018. The keywords used in the search are a combination of the following keywords: University, Ranking, Systems, "Higher Education", Indicators and Criteria. The search was carried out through the services of the Consortium of the Library of Serbia (KOBSON), and it included two major index databases and cited scientific materials (Aghaei Chadegani et al., 2013; Kivinen, Hedman, \& Artukka, 2017; Vught $\&$ Westerheijden, 2010): SCOPUS and Web of Science (WoS).

The search criteria in the systematic review of literature were the type and domain of the study that is the subject of the research, the language of the available scientific material, the origins and years of its publication.

Including search criteria: Reviewed scientific and professional papers as well as final reports arising from the scientific-research projects; articles in the field of global ranking of universities; articles published in English or Serbian that meet defined keyword searches; articles published in the period 2007-2018.

Excluding search criteria: Articles based exclusively on the author's opinion. Also, in the case of articles related to the keywords relating to university ranking systems, it is necessary to exclude all articles in which they are placed outside the context of their comparison and classification.

The next step in the process of drafting a protocol for the implementation of a systematic review of the literature was to define the criteria for evaluating the quality of the identified scientific material. Criteria include the following questions: (1) The goal of the research is unambiguous? (2) Is the exploration method clearly explained? (3) Does the study point to empirical findings? (4) The results of the research have been thoroughly analysed? and (5) Is the study put in the context of other studies or research?

These criteria represent a customised version of the criteria listed in other studies (Kitchenham et al., 2009; Kofod-Petersen, 2014). Each evaluation criterion contains three possible answers (Kitchenham et al., 2009, p. 9): Y (Yes), $\mathrm{P}$ (Partial), and $\mathrm{N}$ (No), which are evaluated respectively by $1,1 / 2$ and 0 . Answer Y (Yes) is a confirmation that the inclusion criterion is unambiguously contained in the study.

The results of the systematic overview of the literature are shown in Table 1.1. It contains data on the results of the search of scientific materials according to defined combinations of search terms in the title and the abstract for two selected index bases.

Table 1.1. Number of hits by search criteria

\begin{tabular}{|c|c|c|c|c|}
\hline \multirow{2}{*}{$\begin{array}{l}\text { Combination of the } \\
\text { search terms }\end{array}$} & \multicolumn{2}{|c|}{ WoS } & \multicolumn{2}{|c|}{ SCOPUS } \\
\hline & Title & Abstract & Title & Abstract \\
\hline $\begin{array}{l}\text { University AND Ranking } \\
\text { AND Systems }\end{array}$ & 26 & 1621 & 4 & 142 \\
\hline $\begin{array}{l}\text { "Higher Education" AND } \\
\text { Ranking AND Systems }\end{array}$ & 7 & 475 & 3 & 38 \\
\hline $\begin{array}{l}\text { University AND Ranking } \\
\text { AND (Indicators OR } \\
\text { Criteria) }\end{array}$ & 17 & 1369 & 3 & 117 \\
\hline $\begin{array}{l}\text { "Higher Education“ AND } \\
\text { Ranking AND (Indicators } \\
\text { OR Criteria) }\end{array}$ & 2 & 382 & 0 & 29 \\
\hline
\end{tabular}

The literature search identified a total of 156 scientific publications and domains of global ranking systems of universities. The primary search identified 146 works, while secondary search included ten additional publications. Apache Open Office Calc, an application for tabular data processing, was used to keep records and encrypt the collected scientific material. Of the total number of collected articles, 25 were identified as redundant and were therefore removed, while the remaining number of publications were then subjected to checks based on pre-determined inclusion/exclusion criteria. 


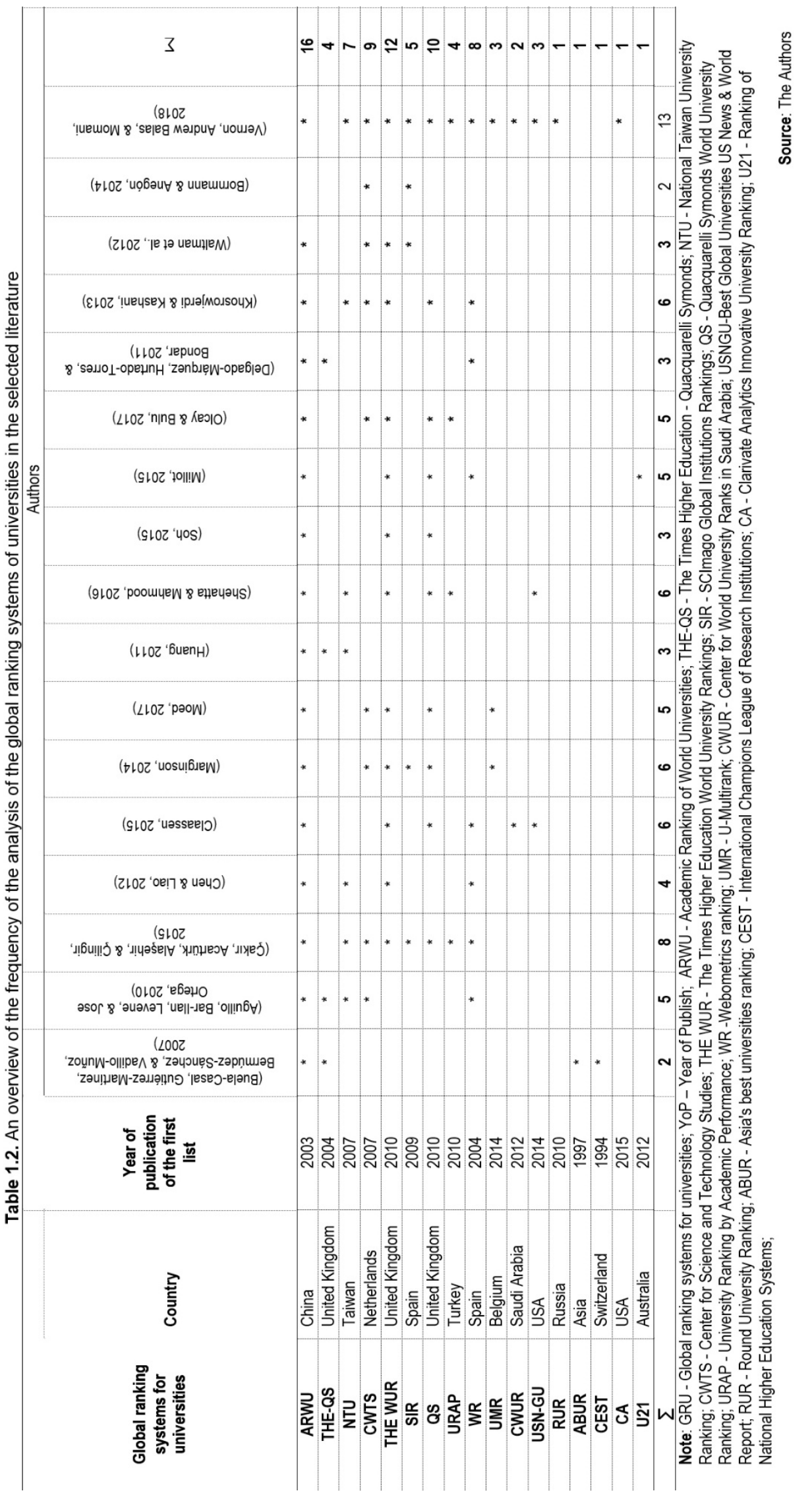


The number of articles that passed the inclusion/exclusion criteria was reduced to 35 . In the end, the last step was to evaluate the scientific material after which 17 articles were included in the systematic review of the literature.

The obtained literature search results show a list of 17 identified global ranking systems of universities. Basic information on ranking systems is given in Table 1.2.

According to the data presented in Table 1.2, it can be seen that the largest number of university ranking systems have been introduced by UK publishing houses (THE-QS, THE WUR, QS), Spain-based research organization (SIR and WR) and by private organization of the United States (USN- GU, CA). A single ranking system represents other countries.

\section{The empirical analysis of the active ranking systems}

The implementation of the empirical analysis of the university ranking system represents the second phase of the research process. This phase involved identifying all relevant information on ranking systems identified within the first phase of the research. Before the data were collected, each ranking system identified within the systematic review of the literature was evaluated based on the criteria shown in Table 2.1. Evaluation of the global ranking systems determined that five ranking systems do not meet the set criteria and are therefore excluded from the further analysis. According to the data in the accompanying table, RUR, CEST, ABUR, CA and CWUR systems represent the least significant rankings in the selected literature and the minimum number of information on the methodology of ranking.

Table 2.1. Criteria for the inclusion and exclusion of global ranking systems from empirical analysis

\section{Inclusion criteria}

- A global ranking system is recognized during the systematic overview of the literature

- The ranking system is placed in the context of other systems

- Basic information on the ranking system is available in the selected literature

- The ranking system is active in the last two years

- Information on ranking results is available on the global Internet.

\section{Exclusion criteria}

- The ranking system is exclusively focused on the ranking of only one study program

- National and regional ranking systems

- The ranking system is solely focused on measuring the position of a particular type of institution, not a university

Source: The Authors
The main reason for the exclusion of the THE-QS, ABUR and CEST system from the further analysis was their inactivity, while the lack of information in the available literature is the reason for omitting CWUR, RUR and CA systems. In the end, the reason for the exclusion of the U21 system is that this system doesn't rank universities, but it does rank the educational systems of countries in relation to the degree of their economic development (Millot, 2015).

\section{Research results}

In table 3.1 are shown the basic empirical information of the active global ranking systems selected by systematic literature review. Of all ranking systems, only UMR and CWTS systems do not base ranking results on a single score. With the highest number of ranking systems, lists of ranked institutions are published once during the year. Further, only the WR system generates lists of the best-ranked universities twice a year, which also contains the largest list with over 110,000 institutions. According to the basket of indicators, most of them contain a UMR system with a list of over 90 indicators, of which 35 indicators are used for measuring global performance.

According to analyses of the selected global ranking system, a total of 114 indicators were identified. In order to facilitate understanding of their purpose, some ranking systems (UMR, THWUR, SIR, CWTS) have joined the grouping of ranking indicators within the input and output dimensions adapted according to the working framework developed by Dill \& Sua (Dill \& Soo, 2005). A detailed analysis of each indicator required the collection of the necessary information on the description of the metrics used, the source of the data, the dimensions and categories to which it relates, the period on which the measurement is made, and the significance they have within each ranking system. After a detailed analysis of all the information collected for each of the identified indicators and the determination of the similarities and differences between them, the number of indicators was reduced to 68 . The display of the regulated indicators has been shown in the table placed in the Appendix. In the same table are shown two ranking systems (CWTS and UMR) that don't use the weighted indicators.

Further, there are two groups of ranking systems that have a similar measurement focus. The first group are consists of NTU, URAP and CWTS ranking systems focused exclusively on the measurement of research performance of the university, while the second group are consists of 
QS, THEWUR and UNS-GU ranking systems whose focus, in addition to research performance, is aimed to measure academic reputation. The narrowest focus has the NTU, URAP and CWTS ranking system which are exclusively focused on measuring research performance in the field of citation, scientific production and scientific excellence. Only SIR and WUR measure web performance of universities. Finally, there are three ranking systems (QS, UMR, THE-WUR) that, according to the input dimension of indicators, recognised international orientation (structure of staff and students) in the total measurement system.

Table 3.1. Basic information on selected global ranking systems for universities

\begin{tabular}{|c|c|c|c|c|c|c|c|c|}
\hline $\begin{array}{l}\text { System of } \\
\text { ranking }\end{array}$ & $\begin{array}{c}\text { Number } \\
\text { of } \\
\text { indicators }\end{array}$ & $\begin{array}{l}\text { System } \\
\text { version }\end{array}$ & $\begin{array}{l}\text { List } \\
\text { size }\end{array}$ & UR & RBF & FoP & $\mathrm{CU}$ & $\begin{array}{l}\text { URL } \\
\text { of the system of ranking }\end{array}$ \\
\hline $\mathrm{ARWU}^{1}$ & 6 & 2017 & 500 & Yes & Yes & Annually & No & $\begin{array}{c}\text { http://www.shanghairanking.com/ARWU- } \\
\text { Methodology-2017.html }\end{array}$ \\
\hline THE WUR & 13 & 2018 & 1000 & Yes & Yes & Annually & No & $\begin{array}{l}\frac{\text { https: } / / \text { wuw timeshighereducation.com/world- }}{\text { university-rankings/methodology-world- }} \\
\text { university-rankings-2018 }\end{array}$ \\
\hline QS & 6 & 2018 & 959 & Yes & Yes & Annually & Yes & $\begin{array}{c}\frac{\text { https://www.topuniversities.com/qs-world- }}{\text { university-rankings/methodology }} \\
\end{array}$ \\
\hline NTU & 8 & 2017 & 814 & Yes & Yes & Annually & No & $\frac{\text { http://nturanking.lis.ntu.edu.tw/methodoloyg/sam }}{\text { pleSelection }}$ \\
\hline URAP & 6 & 2017 & 2500 & Yes & Yes & Annually & No & $\begin{array}{c}\text { http://www.urapcenter.org/2016/methodology.ph } \\
\mathrm{p?q}=1\end{array}$ \\
\hline WR & 4 & 2018 & $\begin{array}{c}1199 \\
1\end{array}$ & Yes & Yes & Semi-annual & No & http://www.webometrics.info/en/Methodology \\
\hline USN-GU & 13 & 2018 & 1250 & Yes & Yes & Annually & No & $\frac{\text { https://umw.usnews.com/education/best-global- }}{\text { universities/articles/methodology }}$ \\
\hline SIR & 12 & 2018 & 3234 & Yes & Yes & Annually & Yes & https://www.scimagoir.com/methodology.php \\
\hline UMR & 35 & 2018 & $\begin{array}{c}1600 \\
+\end{array}$ & No & Yes & Annually & Yes & $\frac{\text { http://wmw.umultirank.org/cms/category/methodo }}{\underline{\text { logy/ }}}$ \\
\hline CWTS & 11 & 2018 & 938 & No & Yes & Annually & No & $\frac{\text { http://www.leidenranking.com/information/indicat }}{\text { ors }}$ \\
\hline
\end{tabular}

\section{Discussion of research results}

The obtained results show that three ranking systems (URAP, CWTS, and NTU) are exclusively research-oriented and contain indicators that rely entirely on bibliometric sources of data. Similarly, ARWU, SIR and USNGU are dominant research ranking systems.

In the case of the ARWU ranking, $90 \%$ of weight refers to measuring the quality of research and research performance. With slightly lower significance in the research measurement system, $75 \%$ of weighted indicators in the SIR and USNGU systems have been directly related to the measurement of research performance. Furthermore, only three systems measure academic and research reputation (QS, THEWUR, USN-GU). Of this, the QS system of ranking assigns $50 \%$ significance to the indicator that measures the academic reputation of teaching and research, as well as the reputation of employers, while only $20 \%$ of weights refers to indicators directly measuring the research performance of the university (citation). Other indicators are related to the measurement of academic quality. Additionally, the measurement of academic quality has been recognized in addition to the QS system in three other global ranking systems. The ARWU contains indicators that measure the quality of students in terms of winning prizes (Nobel, Fields Medal) with 10\% weight in the overall measurement score. On the other hand, THEWUR and UMR ranking systems measure a wider image of academic quality. Regarding the THEWUR ranking system, $33 \%$ of the total weighted indicators refer to the measurement of the reputation of teaching, staff structure, students, and learning environments as the initial characteristics of the university. Within the indicators that measure the research performance, results of the data analysis shown that the highest weight belongs to the indicators of research excellence: ARWU $70 \%$, NTU $40 \%$, URAP $39 \%$, WUR $35 \%$ and USN-GU $32.5 \%$. It should be noted that, in addition to the citation, researchers' excellence take into account indicators that measure a number of the most prestigious world awards (e.g. Nobel and Fields of Medals). 
In addition to research excellence as a measure of the quality of research performance, the citation has recognized as a significant factor in the overall score of ranking results. Accordingly, citation rates as performance indicators have the highest importance in the URAP system with a share of total weighted scores of $36 \%$, followed by the NTU system with $35 \%$ of the share of weighted scores attributed to the citation, THEWUR system with $30 \%$, QS system with $20 \%$, SIR system $13 \%$ of share, USN-GU system $17.5 \%$, and WUR system with share of $10 \%$ of the weighted scores. In addition, scientific productivity measures as outcomes of the research results show presence in five ranking systems (NTU, SIR, THWUR, URAP, USN-GU). The largest sum of weighted coefficients of scientific productivity is identified within the NTU system and refers to $25 \%$ of the total weighted score of the ranked university, while only $5 \%$ of the total weighted score of the same subcategory occurs in the SIR ranking system. Finally, the indicators of collaboration (international, industry), as another critical aspect of the quality of research, have been identified in four ranking systems. The weight of the collaboration indicators in the URAP ranking system is $15 \%$ in the total score, within the USN-GU system is $10 \%$, THEWUR system is $2.5 \%$, and within the SIR system, it is only $2 \%$ of the significance.

Specific ranking systems measure the competitive position of the university from the aspect of innovation, transfer of knowledge and technology. It can be concluded that the UMR system attaches the most significant attention to the promotion of the quality of universities from the aspect of innovation development and technology transfer, as it includes indicators for measuring the approved patents, patents developed in cooperation with industry, launching start-ups and spin-off companies and measuring technological impacts (citation in the patents). Of all ranking systems, only the SIR system attaches a weight coefficient to the result indicators $(5 \%)$ that measure the technological impact. On the other hand, the WUR ranking system gives only $2.5 \%$ weighted score to an indicator that measures the institutional income derived from the industry as a reflection of technology transfer.

Student mobility as an indicator of international orientation has recognised only within the UMR ranking system, while indicators that measure the visibility of universities on a global Internet network have been identified within the SIR and WR ranking systems. The overall weight of indicators for measuring the visibility of universities within the WR ranking system is $55 \%$, while in the SIR system this share is lower and it is $20 \%$ of the total weight.

In table 4.1 are shown the ranking systems with information of the percentage of the share of the weighted indicators in relation to the total measurement system, according to subcategories, categories and dimensions of indicators. As mentioned earlier in this paper, only CWTS and UMR systems don't use weighted scores of university rank. It was only noted that their measure is covered by some of the categories noted in table 4.1. According to the obtained results, it can be concluded that the indicators of the output dimension have the highest share in the measurement system, with $93 \%$ of the total sum of the weight of all indicators. According to categories, the research indicators have the highest importance of total share of $67.93 \%$ with the overall measurement system. The value of the research category in the sum with the value of the category of "innovation, technology transfer and technological impact" reaches $68.87 \%$ share of total weight. The following is a category of reputation with a contribution of $13.5 \%$ in the overall weighted system, while $9.37 \%$ of share in total weight is related to indicators that measure the web performance of the university. The share of the other subcategories of the indicators is less than $4 \%$. Of all indicator categories, the "student structure" category, which belongs to the dimension of entry, has the lowest share of $0.6 \%$ of the total weight of indicators.

In addition to the abovementioned, there are also different sources of data identified in the process of empirical analysis of the ranking system. They can all be viewed from the aspect of the database being used (e.g. WoS, SCOPUS, GSC); Institutions, offices or agencies that provide the necessary data for calculating scores (eg. patents offices, higher education institutions, national statistical data processing agencies, etc.); Data based on Internet sources (Majestic SEO, Ahref SEO, Yahoo Explorer, Google); and finally, the data obtained through the survey (reputation, satisfaction).

By a comparative analysis of the focus of measurement of the selected global ranking systems, and by identifying the most important areas of evaluation from the aspect of dimensions and categories of identified ranking criteria, an answer to the second research question was provided. 
Table 4.1. The proportion of the weighted sum of indicators in the total measurement system

\begin{tabular}{|c|c|c|c|c|c|c|c|c|c|c|c|c|c|c|}
\hline \multirow[b]{2}{*}{$\frac{.}{\frac{.}{0}}$} & \multirow[b]{2}{*}{ Category } & \multirow{2}{*}{ Subcategory } & \multicolumn{10}{|c|}{ Share of weighted coefficients of global ranking systems } & \multirow[b]{2}{*}{$\frac{\frac{\pi}{\sigma}}{\frac{\sqrt{W}}{a}}$} & \multirow[b]{2}{*}{$\frac{\underline{a}}{\frac{0}{\omega}}$} \\
\hline & & & 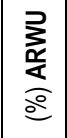 & 罂 & $\frac{2}{2}$ & $\frac{\mathscr{0}}{\stackrel{0}{0}}$ & $\frac{\frac{\alpha}{\omega}}{\stackrel{\varrho}{\varrho}}$ & 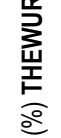 & $\sum_{\zeta}^{\alpha}$ & 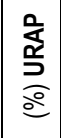 & 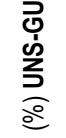 & 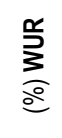 & & \\
\hline \multirow{5}{*}{ 흘 } & \multirow{2}{*}{$\begin{array}{l}\text { Initial } \\
\text { characteristics of } \\
\text { the University }\end{array}$} & Group size & - & & - & 2.5 & - & 0.6 & & - & - & - & \multirow[b]{2}{*}{3.69} & \multirow{5}{*}{7.0} \\
\hline & & $\begin{array}{l}\text { Study program and the number } \\
\text { of position }\end{array}$ & - & & - & 0.6 & - & - & * & - & - & - & & \\
\hline & Staff & Structure of staff & - & & - & 0.6 & - & 1.1 & * & - & - & - & 1.69 & \\
\hline & Students & Structure of students & - & & - & - & - & 0.6 & * & - & - & - & 0.60 & \\
\hline & $\begin{array}{l}\text { Financial } \\
\text { resources }\end{array}$ & $\begin{array}{l}\text { Revenues (total, ratio, } \\
\text { development, research) }\end{array}$ & - & & - & - & - & 1.0 & * & - & - & - & 1.04 & \\
\hline \multirow{15}{*}{$\begin{array}{l}\text { 눔 } \\
\text { 咅 }\end{array}$} & Graduated & Graduating on time & - & & - & - & - & - & * & - & - & - & & \multirow{14}{*}{93.0} \\
\hline & & Degrees awarded & - & & - & - & - & - & * & - & - & - & 0 & \\
\hline & Quality of & Awards & 1.2 & & - & - & - & - & & - & - & - & & \\
\hline & education & Employment & - & & - & - & - & - & * & - & - & - & 1.25 & \\
\hline & Research & $\begin{array}{l}\text { Publication (international } \\
\text { collaborative publications, } \\
\text { collaborative publication, } \\
\text { articles, conferences) }\end{array}$ & 2.5 & * & 3.1 & - & 1.5 & 1.1 & * & 3.1 & 3.1 & - & 67.93 & \\
\hline & & Citations & - & * & 4.4 & 2.5 & 1.6 & 3.7 & * & 4.5 & 2.2 & 1.2 & & \\
\hline & & Research excellence & 8.7 & * & 5.0 & - & 6.2 & - & * & 4.9 & 4.1 & 4.4 & & \\
\hline & \multirow{3}{*}{$\begin{array}{l}\text { Innovation, } \\
\text { technology } \\
\text { transfer and } \\
\text { technology } \\
\text { impact }\end{array}$} & Intellectual property rights & - & & - & - & - & - & * & - & - & - & \multirow{3}{*}{0.94} & \\
\hline & & Technology transfer & - & & - & - & - & 0.3 & * & - & - & - & & \\
\hline & & Technology impact & - & & - & - & 0.6 & - & * & - & - & - & & \\
\hline & \multirow[t]{2}{*}{ Reputation } & $\begin{array}{l}\text { Academic reputation (research, } \\
\text { teaching) }\end{array}$ & - & & - & 5.0 & - & 4.1 & & - & 3.1 & - & \multirow[t]{2}{*}{13.50} & \\
\hline & & Employer reputation & - & & - & 1.2 & - & - & & - & - & - & & \\
\hline & $\begin{array}{l}\text { International } \\
\text { collaboration }\end{array}$ & Mobility & - & & - & - & - & - & * & - & - & - & 0 & \\
\hline & Web performance & Web performance & - & & - & - & 2.5 & - & & - & - & 6.9 & 9.37 & \\
\hline & & $\sum(\%)$ & 12.5 & - & 12.5 & 12.5 & 12.5 & 12.5 & - & 12.5 & 12.5 & 12.5 & & 100 \\
\hline
\end{tabular}

\section{Concluding remarks}

Numerous indicators of global ranking systems of universities have been identified in this paper. A detailed analysis of the ranking system is presented according to the focus of their measurement based on the identified indicators. According to the obtained results, the most significant similarity is observed between the NTU, URAP and CWTS ranking systems, since they are systems which rely exclusively on bibliometric data sources and use the same data sources (WoS) for determining values by indicators.

The most significant number of global ranking systems dominantly puts its focus in the context of measuring research performance as the crucial indicator of the quality and competitiveness of universities. There are certain standpoints regarding the perception of the research performance. Thus, Vernon et al. (2018) observe the research performance from the aspect of citation, scientific productivity and innovation.

In the context of the measurement scale of the ranking system within this comparative study, the research performance was observed from two aspects. On the one hand, as a measure of citation, scientific production and scientific excellence (ARWU, THE WUR, QS, NTU, URAP, WR, USN-GU, SIR, UMR, CWTS), and on the other hand as a measure of innovation, technology transfer and technological impact (THEWUR, SIR, UMR) as a result of scientific research. Additionally, the global ranking systems of the 
university point out some of the academic quality measures as a focus of measurement, where the focus is on reputation measurement (QS, THEWUR, UNS-GU) and the quality of teaching and learning environment (THE WUR). Also, the initial characteristics of the institution are an essential indicator of quality. Thus, QS and THEWUR, as an essential measure of the initial characteristics, emphasise the study programs and the number of places in study programs, as well as monitoring the relationship between the number of students and staff. Finally, the focus of measurement of the observed ranking systems is also the domain of the university's international orientation in terms of student mobility and staffing (UMR), as well as the focus on measuring web performance (SIR, WR) of the university through link analysis.

\section{Acknowledgements}

The results of the empirical study are the part of the research conducted for the needs of the doctoral dissertation titled "The Reference Model of Business Processes of the University for the Advancement of Their Competitiveness", submitted at the Faculty of Economics in Subotica at the University of Novi Sad.sm

\section{References}

Aghaei Chadegani, A., Salehi, H., Md Yunus, M. M., Farhadi, H., Fooladi, M., Farhadi, M., \& Ale Ebrahim, N. (2013). A comparison between two main academic literature collections: Web of Science and Scopus databases. Asian Social Science, 9 (5), 18-26. https://doi.org/10.5539/ass.v9n5p18

Aguillo, I. F., Bar-llan, J., Levene, M., \& Jose Ortega, L. (2010). Comparing university rankings. Scientometrics, 85 (1), 243-256. https://doi.org/10.1007/s11192-010-0190-z

Bolton, C., Machová, V., Kovacova, M., \& Valaskova, K. (2018). The Power of Human-Machine Collaboration: Artificial Intelligence, Business Automation, and the Smart Economy. Economics, Management, and Financial Markets, 13 (4), 51-56. https://doi.org/10.22381/EMFM13420184

Bornmann, L., \& Anegón, F. de M. (2014). What Proportion of Excellent Papers Makes an Institution One of the Best Worldwide? Specifying Thresholds for the Interpretation of the Results of the SCImago Institutions Ranking and the Leiden Ranking. Journal of the Association for Information Science \& Technology, 65 (4), 732-736. https://doi.org/10.1002/asi.23047

Buela-Casal, G., Gutiérrez-Martínez, O., BermúdezSánchez, M. P., \& Vadillo-Muñoz, O. (2007). Comparative study of international academic rankings of universities. Scientometrics, 71 (3), 349-365. https://doi.org/10.1007/s11192-007-1653-8

Çakır, M. P., Acartürk, C., Alaşehir, O., \& Çilingir, C. (2015). A comparative analysis of global and national university ranking systems. Scientometrics, 103 (3), 813-848. https://doi.org/10.1007/s11192-015-1586-6
Chen, K. hua, \& Liao, P. yu. (2012). A comparative study on world university rankings: A bibliometric survey. Scientometrics, 92 (1), 89-103. https://doi.org/10.1007/s11192-012-0724-7

Chessell, D. (2018). The Jobless Economy in a Post-Work Society: How Automation Will Transform the Labor Market. Psychosociological Issues in Human Resource Management, 2 (6), 74-79.

https://doi.org/10.22381/PIHRM6220187

Claassen, C. (2015). Measuring university quality. Scientometrics, (April), 793-807. https://doi.org/10.1007/s11192-015-1584-8

Delgado-Márquez, B. L., Hurtado-Torres, N. E., \& Bondar, Y. (2011). Internationalization of Higher Education: Theoretical and Empirical Investigation of Its Influence on University Institution Rankings. Revista de Universidad y Sociedad Del Conocimiento, 8 (2), 265284. https://doi.org/10.7238/rusc.v8i2.1069

Dill, D. D., \& Soo, M. (2005). Academic quality, league tables, and public policy: A cross-national analysis of university ranking systems. Higher Education, 49 (4), 495-533. https://doi.org/10.1007/s10734-004-1746-8

Grossman, T. (2018). The Rise of an Automated Jobless Society: Do Cutting-Edge Technologies Expel Workers Swifter than the Economy Can Identify New Jobs for Them? Psychosociological Issues in Human Resource Management, 6 (2), 62-67. https://doi.org/10.22381/PIHRM6220185

Huang, M.-H. (2011). A Comparison of Three Major Academic Rankings for World Universities: From a Research Evaluation Perspective. Journal of Library and Information Studies, 9 (1), 1-25. https://doi.org/10.1023/A:1021225514599

Khosrowjerdi, M., \& Kashani, Z. S. (2013). Asian top universities in six world university ranking systems. Webology, 10 (2), 1-9. Retrieved April, 18, 2019 from: http://www.webology.org/2013/v10n2/a114.pdf

Kitchenham, B. (2004). Procedures for performing systematic reviews. In Keele, UK, Keele University. Retrieved April, 18, 2019 from: https://pdfs.semanticscholar.org/d36f/e9d7839596d58fa 008121db57dc7cadda338.pdf

Kitchenham, B., Pearl Brereton, O., Budgen, D., Turner, M., Bailey, J., \& Linkman, S. (2009). Systematic literature reviews in software engineering - A systematic literature review. Information and Software Technology, 51 (1), 715. https://doi.org/10.1016/j.infsof.2008.09.009

Kivinen, O., Hedman, J., \& Artukka, K. (2017). Scientific publishing and global university rankings. How well are top publishing universities recognized? Scientometrics, 112 (1), 679-695. https://doi.org/10.1007/s11192-017-2403-1

Kofod-Petersen, A. (2014). How to do a Structured Literature Review in computer science. Retrieved April, 18, 2019 from: https://www.researchgate.net/publication/265158913_H ow_to_do_a_Structured_Literature_Review_in_comput er_science

Marginson, S. (2014). University rankings and social science. European Journal of Education, 49 (1), 45-59. https://doi.org/10.1111/ejed.12061

Millot, B. (2015). International rankings: Universities vs. higher education systems. International Journal of Educational Development, 40, 156-165. https://doi.org/10.1016/j.ijedudev.2014.10.004 
Moed, H. F. (2017). A critical comparative analysis of five world university rankings. Scientometrics, 129 (2), 1-24. https://doi.org/10.1007/s11192-016-2212-y

Olcay, G. A., \& Bulu, M. (2017). Is measuring the knowledge creation of universities possible?: A review of university rankings. Technological Forecasting and Social Change, 123, 153-160. https://doi.org/10.1016/j.techfore.2016.03.029

Shehatta, I., \& Mahmood, K. (2016). Correlation among top 100 universities in the major six global rankings: policy implications. Scientometrics, 109 (2), 1231-1254. https://doi.org/10.1007/s11192-016-2065-4

Soh, K. (2015). What the Overall doesn't tell about world university rankings: examples from ARWU, QSWUR, and THEWUR in 2013. Journal of Higher Education Policy and Management, 37 (3), 295-307. https://doi.org/10.1080/1360080X.2015.1035523
Usher, A., \& Savino, M. (2007). A global survey of university ranking and league tables. Higher Education in Europe, 32 (1), 5-15.

https://doi.org/10.1080/03797720701618831

Vernon, M. M., Andrew Balas, E., \& Momani, S. (2018). Are university rankings useful to improve research? $A$ systematic review. PLoS ONE, 13 (3), 1-15. https://doi.org/10.1371/journal.pone.0193762

Vught, F. A. van, \& Westerheijden, D. F. (2010). Multidimensional ranking: a new transparency tool for higher education and research. Higher Education Management and Policy, 22 (3), 1-26. https://doi.org/10.1787/hemp-22-5km32wkjhf24

Waltman, L., Calero-medina, C., Kosten, J., Noyons, E. C. M., Tijssen, R. J. W., Eck, N. J. Van, ... Wouters, P. (2012). The Leiden Ranking 2011/2012: Data collection, indicators, and interpretation. Journal of the Association for Information Science and Technology, 63 (12), 24192432. https://doi.org/10.1002/asi.22708

\section{\ Correspondence}

Nemanja Lukić
University of Novi Sad, Faculty of Education in Sombor
Podgorička 4, 25101, Sombor, Serbia
E-mail: nemanja.lukic@pef.uns.ac.rs




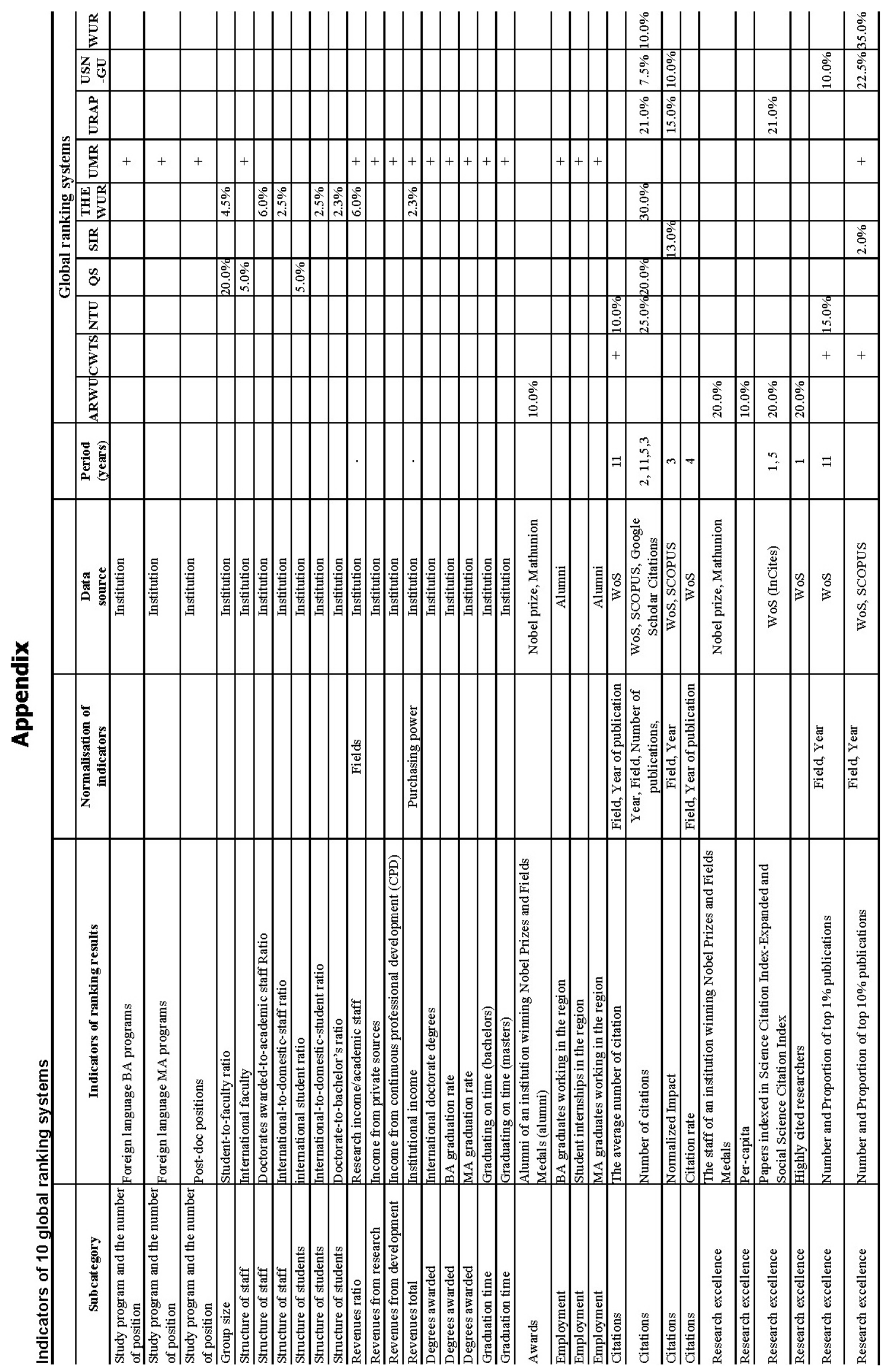




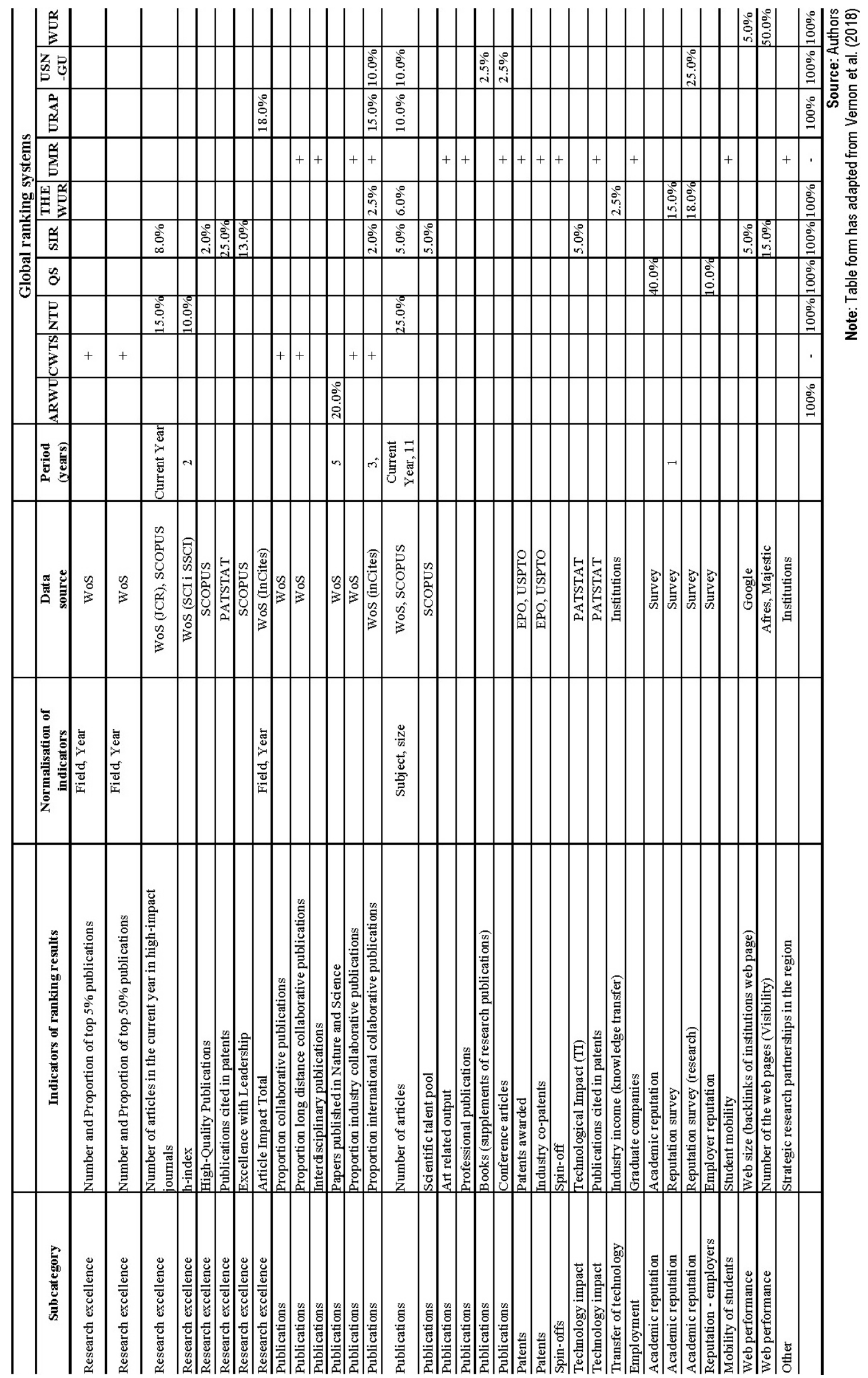

